\title{
Power System Loading Margin Enhancement by Optimal STATCOM Integration:a case study
}

\author{
Sasidharan Shreedharan \\ MES College of Engineering, Kerala \\ Tibin Joseph \\ Cardiff University \\ Sebin Joseph \\ Al-Ahleia Switchgear Co., Kuwait
}

See next page for additional authors

Follow this and additional works at: https://arrow.tudublin.ie/engscheleart2

Part of the Electrical and Computer Engineering Commons

\section{Recommended Citation}

Sreedharan, S., Joseph, T, Joseph, S. et al (2019). Power system loading margin enhancement by optimal STATCOM integration: a case study. Computers and Electrical Engineering, 81:106521. doi:10.1016/ j.compeleceng.2019.106521

This Article is brought to you for free and open access by the School of Electrical and Electronic Engineering at ARROW@TU Dublin. It has been accepted for inclusion in Articles by an authorized administrator of ARROW@TU Dublin. For more information, please contact arrow.admin@tudublin.ie, aisling.coyne@tudublin.ie, gerard.connolly@tudublin.ie.

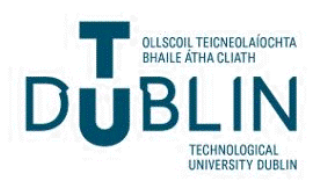




\section{Authors}

Sasidharan Shreedharan, Tibin Joseph, Sebin Joseph, Chittesh Veni Chandran, Vishnu J., and Vipin Das P 


\title{
Power system loading margin enhancement by optimal STATCOM integration - A case study
}

\author{
Sasidharan Sreedharan ${ }^{a}$, Tibin Joseph ${ }^{b, *}$, Sebin Joseph ${ }^{c}$, \\ Chittesh Veni Chandran ${ }^{\mathrm{d}}$, Vishnu J ${ }^{\mathrm{e}}$, Vipin Das $\mathrm{P}^{\mathrm{f}}$ \\ ${ }^{a}$ MES College of Engineering, Kerala, India \\ b School of Engineering, Cardiff University, Wales CF24 3AA, UK \\ ${ }^{\mathrm{c}}$ Al-Ahleia Switchgear Co., Kuwait \\ d Dublin Institute of Technology, Dublin, Ireland \\ ${ }^{\text {e }}$ Kerala State Electricity Board, Kerala, India \\ ${ }^{\mathrm{f}}$ Motilal Nehru National Institute of Technology, Allahabad, India
}

\section{A R T I C L E I N F O}

\section{Article history:}

Received 12 March 2019

Revised 21 November 2019

Accepted 22 November 2019

Available online 26 December 2019

\section{Keywords:}

Optimization algorithms

Genetic algorithm

Optimal placement

Loading margin

Hosting capacity

Power system security and stability

\begin{abstract}
A B S T R A C T
Safe and secure network operation with acceptable voltage level has become a challenging task for utilities requiring corrective measures to be implemented. Network upgrades using Flexible Alternating Current Transmission System devices are being considered to serve this purpose. To this end, static loading margin enhancement by optimal static synchronous compensator (STATCOM) allocation to enhance the power transfer capability with minimal voltage variation is presented. Maximum loadability is formulated as an optimization problem, subjected to voltage and small-signal stability constraints. Stability indices are presented and incorporated with the optimization problem to ensure secure operation under maximum loading. The scheme is executed with the IEEE system and an Indian utility network. Improved voltage regulation with different loading condition was achieved for both test networks, with the service rendered by the optimally placed STATCOM. Moreover, it facilitates an additional 50\% capacity release in both test systems for hosting the active power and loads.
\end{abstract}

(c) 2019 Elsevier Ltd. All rights reserved.

\section{Introduction}

The traditional power grid is compelled to operate at full capacity due to increased load demands and renewable energy uptake. This in effect creates an unfavourable risk of potential outages or blackout in the power systems, adversely affecting the voltage stability [1]. Many incidents of system blackout have been reported which are caused by voltage collapse $[1,2]$. When analyzing the root cause of these problems, the network reactive power imbalance is identified as the major contributor to voltage instability [2]. Hence, the existing power system has to be strengthened to accommodate the distributed renewable resources, load demand and the reactive power imbalance. Conventional system uprating or upgrading using compensation devices, installing new lines or substations are very expensive procedure and hence would require to ensure maximum utilization by optimal sizing and placing of the additional devices [3].

\footnotetext{
This paper is for regular issues of CAEE. Reviews processed and recommended for publication to the Editor-in-Chief by Area Editor Dr. E. Cabal-Yepez.

* Corresponding author.

E-mail address: josepht@cardiff.ac.uk (T. Joseph).
} 


\section{Nomenclature}

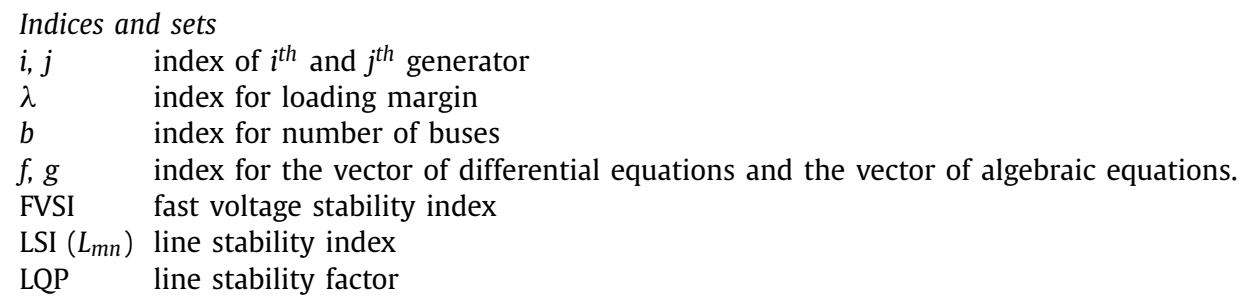

Data and parameters

$P_{G}$ and $Q_{G}$ real and reactive power delivered to the system by substation generator

$P_{s h}$ and $Q_{s h}$ real and reactive power through STATCOM

$P_{L}$ and $Q_{L}$ real and reactive power demand by the load

$V_{s h}<\theta_{s h} \quad$ STATCOM terminal complex voltage

$I_{\text {sh }} \quad$ STATCOM terminal current

$V_{i}<\theta_{i} \quad$ Bus- $i$ complex voltage

$\delta \quad$ phase angle

$Z_{\text {sh }} \quad$ shunt transformer impedance

$V_{\text {ref }} \quad$ the bus voltage control reference

$\mathrm{C} \quad$ cost Function

$N_{b} \quad$ number of buses

$A_{s} \quad$ statematrix

$A_{c} \quad$ Complete Jacobian matrix

$\mathrm{Z} \quad$ total impedance of the system

$\mathrm{X}$ total reactance of the system

Abbreviation

STATCOM Static Synchronous Compensator

SC Synchronous Compensators

TCSC Thyristor controlled Series Compensator

SSSC Static synchronous Series Compensator

SVC Static Var Compensator

FACTS Flexible Alternating Current Transmission System

CTS Central Travancore System

AVR Automatic Voltage Regulator

KSEB Kerala State Electricity Board

ABC Artificial Bee Colony

ACOR Continuous Ant Colony Optimization

DE Differential Evolution

HS Harmony Search

GA Genetic Algorithm

PSO Particle Swarm Optimization

The stability margin of an existing network can be enhanced by employing advanced power electronics technologies. Flexible Alternating Current Transmission System (FACTS) devices, in particular, static synchronous compensator (STATCOM) provides technical solutions to such scenarios [1-3]. Additional benefits rendered by power electronic-based FACTS devices compared to capacitor banks and synchronous compensators (SC) lies in their faster dynamic response [4,5]. Moreover, with these devices utilities will benefit from a cost-saving alternative for voltage regulation and enhanced hosting capability. However, for getting superior operation from these devices, strategic placement of these controllers are crucial [1-3]. To this end, optimization-based methods are used for deploying FACTS devices in the network to enhance the loadability and reliability margins $[3,4]$.

Stochastic algorithms based methods were applied for selecting the suitable sizing and setting of shunt FACTS controllers to enhance the voltage stability [3-9]. Application of Genetic Algorithm (GA) for solving a range of power system problems has been reported in the literature [8-11]. Owing to its simplicity in application and satisfactory operation in identifying global and near-global optimal solutions, GA is used in the controller variable optimization [9-12]. However, long computational time limits GAs widespread application and paved the way for more computationally efficient optimization algorithms $[8,9]$. This includes swarm optimization such as particle swarm optimization (PSO), ant colony optimization (ACO) and harmony search algorithm (HS). These schemes, on the other hand, suffer from partial optimal solutions and are therefore slow 
in convergence [7-10]. Alternatively, Artificial Bee Colony (ABC) is proposed to find the optimal STATCOM allocation for damping low-frequency oscillations [10]. Even though good in performance, they lack in the convergence rate and a good balance is required between the abilities of the parameter sets for the successful delivery of optimization solution [11-13]. Evolutionary algorithms have been proposed for finding the optimal location of STATCOM in a distribution network [11,12]. Even though simple in adaptation, easy to implement with a minimal number of controller settings and offers faster convergence, they are vulnerable to the premature convergence and might stuck in sub-optimal solutions [13]. To this end, GA has been selected in this study owing to its proven all-round performance and simplicity over the other optimization algorithms.

In addition, the voltage stability margin can be enhanced by using devices like STATCOM, static synchronous series compensator (SSSC) and thyristor controlled series compensator (TCSC) [17,18]. However, in most cases, the level of reactive power requirements is not sufficient to enhance the network static loading and stability limits of the 'weakest node' or 'sensitive bus' [17]. The weakest bus is one that is ranked highest among other buses as it has limited capability to withstand load prior to voltage collapse $[20,21]$. To recognise the most sensitive bus in a standard IEEE test network, an approach called $L$ - index has been used, which rely on the sensitivity analysis as discussed in [17,20,21].

Following this line, it is clear that reactive power compensation is essential to guarantee stable operation for complex power systems $[14,15]$. In practical systems, the optimal size of dynamic compensation rating is considered as $\pm 1 \%$ of the short-circuit MVA of the optimal bus location as reported in [15]. The optimization criteria mainly rely on: the overall generation costs, the investment cost, total losses, the increase in maximum load and transient stability enhancement of the system $[14,15]$.

To the best of the authors knowledge, most of the research works have been focused on using FACTS devices on loadability enhancement. Simultaneously, the stable operating performance in terms of voltage and small-signal stability constraints at heavy system loading has not received much attention until now. To contribute to these efforts we have performed the following novel tasks:

1. An algorithm based on GA is presented to enhance the loading margin of the power system network using STATCOM.

2. Small-signal and voltage stability margins are incorporated to ensure stable grid operation while increasing the loading margin.

3. A practical case study with the proposed scheme is introduced to evaluate the effectiveness, capacity enhancement and operational benefits.

The remaining sections of the article contain Section 2 highlighting modelling of STATCOM. The proposed robust controller is introduced in Section 3, with Section 4 defining the optimization problem with associated constraints. The static and dynamic results are presented in Section 5 along with the description of the case study and Section 6 presents a comparison of network parameters for different optimization algorithms. Finally, Section 7 discusses the findings were conclusions are drawn.

\section{Modeling of STATCOM controllers}

STATCOM belongs to the family of shunt connected FACTS devices. STATCOM can manage effectively the network voltage by generating (capacitive) and absorbing (inductive) reactive power, depending on the behaviour of network voltage levels. This, in turn, allows the operators to maintain the voltages at Point of common coupling (PCC) to the set-point level by regulating the magnitude and angle of the internal voltage of the STATCOM, thanks to its excellent dynamic performance and short-term response [15-17]. STATCOM's structural schematic, equivalent representation and dynamic model are shown in Figs. 1(a)-(c) respectively $[15,16,19]$. The equivalent representation in Fig. 1(b) uses a controllable voltage source $V_{s h} \angle \theta_{s h}$ and assumes a constant regulator time period. The voltage $V_{s h}$ is adjusted to set the local bus voltage and the power flow control using STATCOM as described in Eq. (1) with active power exchange through the DC link with achieved using Eq. (2). The Eq. (3) shows the analytical model of the bus control expression of STATCOM.

$$
\begin{aligned}
& P_{s h}+j Q_{s h}=V_{s h} \angle \theta_{s h}\left(\frac{V_{i} \angle \theta_{i}-V_{s h} \angle \theta_{s h}}{Z_{s h}}\right)^{*} \\
& P E=\operatorname{Re}\left(V_{s h} I_{s h}^{*}\right)=0 \\
& V_{i}-V_{r e f}=0
\end{aligned}
$$

Here, $V_{i} \angle \theta_{i}$ and $V_{s h} \angle \theta_{s h}$ represents complex voltages at the $i$ th bus and STATCOM terminal; $P_{s h}+j Q_{s h}$ is the STATCOM apparent power; $Z_{s h}$ is the shunt transformer impedance, and $V_{\text {ref }}$ the bus voltage control reference.

\section{Modeling of the proposed robust controller}

A novel robust controller powered by GA is proposed in this work. The controller serves to maximize the loading condition of the system while incorporating stability limits. Fig. 2 shows the block schematic of the control scheme implemented to achieve the objective. The controller fetches data from the test network, and after processing fed back it as a control 


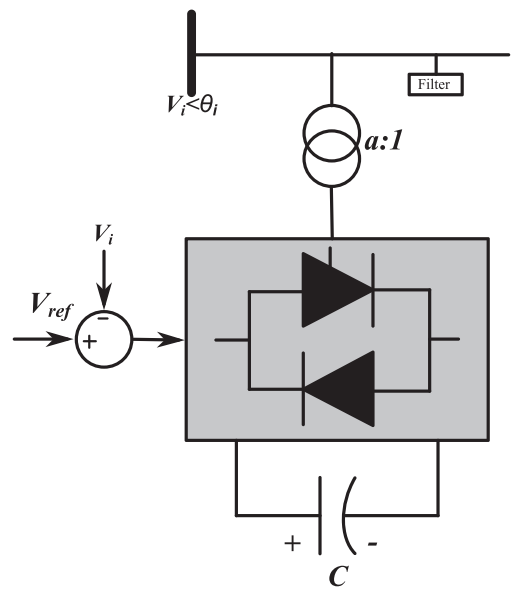

(a)

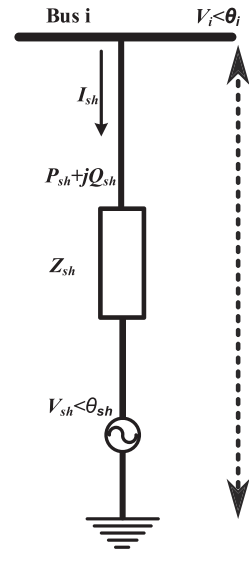

(b)

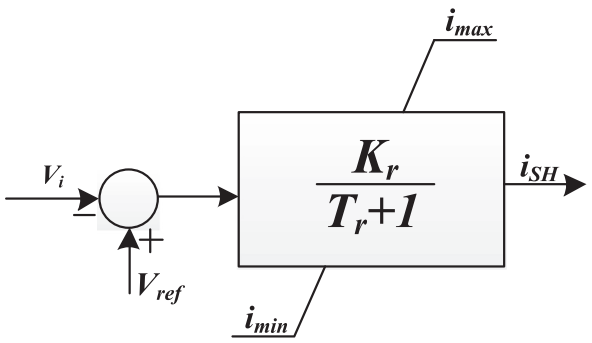

(c)

Fig. 1. (a) Basic structure of a STATCOM, (b) Equivalent circuit of a STATCOM connected to a local bus (c) Control scheme.

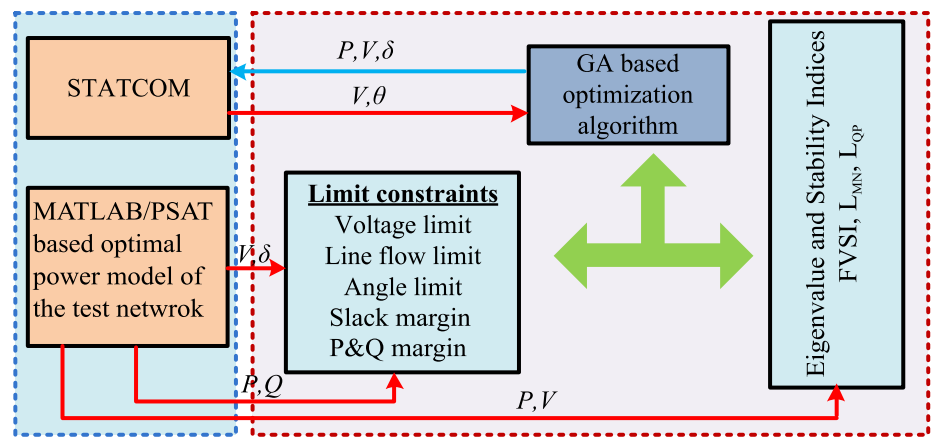

Fig. 2. Proposed robust controller block schematic.

signal to STATCOM. The basic logic of the GA is; the generation of the best individual is to be carried over to the next generation and further with the best trait propagating upward. Here, GA is utilized as a tool for optimizing the system and to maximize the objective function.

The notion 'optimize the system' is used in the sense that a stable operating condition without violating any system security or stability limits. This is achieved by evaluating limit and stability constraints for every offspring (solution) in the population and disregarding the non-feasible solution. The best trait or the positive trait is the objective, which for the present scenario is the loadability. The algorithm will always try to use solution with high loadability as best set of offspring to form the next generation that does not violate any constraints. This mimics the natural selection found in nature and has been applied to solve various other optimization problems [23] and its simple nature and ease of implementation have widespread its popularity. The flowchart proposed using the GA algorithm to seek the optimal location STATCOM is given in Fig. 3.

\section{Defining optimization problem}

\subsection{Formulation of optimization objective}

The main purpose of the objective function is to identify a suitable location to place STATCOM to achieve a safe and maximum loadability at all the buses in a conventional network. This has to be done fulfilling the system stable operational constraints. The power demand of loads in terms of real and reactive components are simultaneously uprated in terms of $(\lambda)$, the loadability factor. The rate at which $\lambda$ changes to the maximum value from the base case value ( 1 p.u.) without rendering the system unstable is considered as the maximum loadability of the system. The final function is a single objective targeting to maximize the objective by optimally placement of STATCOM with a set of constraints and can be expressed as [17,19]:

$$
\left.\begin{array}{l}
F=\operatorname{Max}(\lambda) \\
\lambda=f(x, y)
\end{array}\right\}
$$




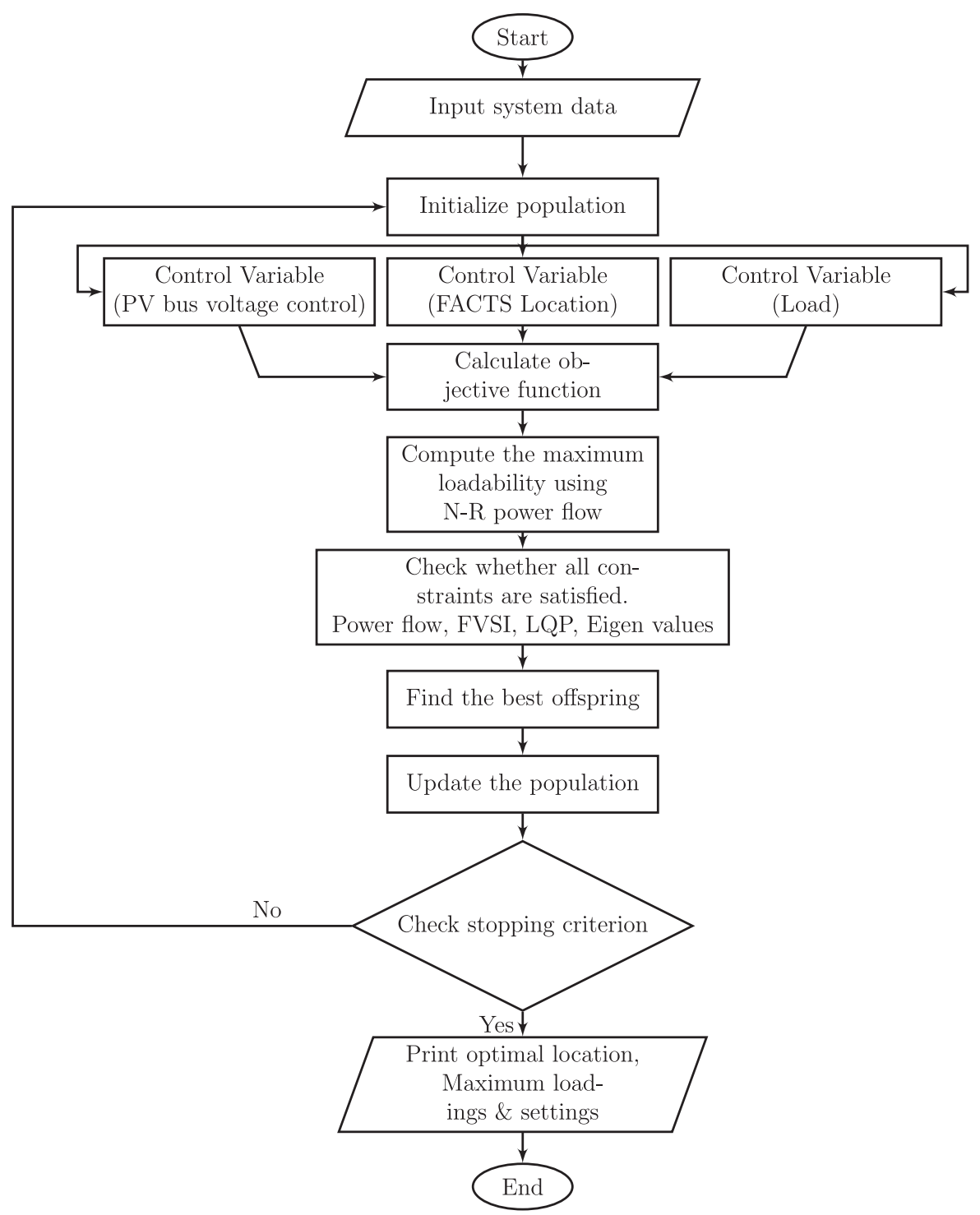

Fig. 3. Flowchart for maximum loadability assessment using robust controller.

Here $\lambda$ is the loadability factor in p.u. bounded by the security and stability constraints. $\lambda$ is considered as a function of the dependent (voltage, load, load angle etc.) and independent variables respectively. The optimization varies these dependent variables to obtain a solution space. Also, the cost function has an inverse relation with loadability.

\subsubsection{Equality constraints:}

The equality constraints that bounds the optimization problem in Eq. (4) are the total real and reactive power of the generators given in Eq. (5) in the system used to maintain the load-generation profile.

$$
\begin{aligned}
& P_{i}=P_{G_{i}}-P_{D_{i}}-\left|V_{i}\right| \sum_{j=1}^{N_{b}}\left|V_{j}\right|\left|Y_{i j}\right| \cos \left(\delta_{i}-\delta_{j}-\theta_{i j}\right) \\
& Q_{i}=Q_{G_{i}}-Q_{D_{i}}-\left|V_{i}\right| \sum_{j=1}^{N_{b}}\left|V_{j}\right|\left|Y_{i j}\right| \sin \left(\delta_{i}-\delta_{j}-\theta_{i j}\right)
\end{aligned}
$$

Here $P_{i}$ and $Q_{i} ; P_{G_{i}}$ and $Q_{G_{i}}$; and $P_{D_{i}}$ and $Q_{D_{i}}$ represents real and reactive power injection; generation and demand by the load with $N_{b}$ representing the total number of buses. 
4.1.2. Inequality constraints:

To ensure stable grid operation limits of minimum and maximum operating regions of different power system components are required as inequality constraints. These includes: the generator active and reactive powers $\left(\left(P_{G_{i}}\right)\right.$ and $\left.\left(Q_{G_{i}}\right)\right)$ limits, voltage and phase angle $\left(\left(V_{i}\right)\right.$ and $\left.\left(\delta_{i}\right)\right)$ limits which are constrained as follows.

$$
\left.\begin{array}{l}
P_{G_{i}}^{\text {min }} \leq P_{G_{i}} \leq P_{G_{i}}^{\text {max }} \\
Q_{G_{i}}^{\text {min }} \leq Q_{G_{i}} \leq Q_{G_{i}}^{\text {max }} \\
V_{i}^{\text {min }} \leq V_{i} \leq V_{i}^{\text {max }} \\
\delta_{i}^{\text {min }} \leq \delta_{i} \leq \delta_{i}^{\text {max }}
\end{array}\right\}
$$

The line flow limit expressed as a transmission loading constraint $\left(P_{i j}\right)$ is given as

$$
\left|P_{i j}\right| \leq P_{i j}^{\max }
$$

The inequality constraint considering the loading factor limit at each bus can be written as:

$$
1 \leq \lambda \leq \lambda^{\max }
$$

A safe limit is required for the loading factor to facilitate a stable bus loading.

\subsubsection{System stability depended constraints}

To facilitate a stable loading margin based controller development, the system stability constraints are incorporated into the optimization problem. This will ensure a stable and secure system loading enhancement through the appropriate control response rendered by the proposed algorithm. The stability constraints considered in this study are:

- Small signal stability: To ensure stable operation under small-disturbances such as load changes, eigenvalue based small-signal stability assessment is utilized [18,19]. Eigenvalue analysis discloses significant relation among state variables of a system as well as gives an intuition into the electromechanical dynamics of the network. The controllable generators, loads and associated components in the network are modelled as a set of algebraic and differential equations (DAE) represented by (9) [19]:

$$
\begin{aligned}
\dot{x} & =f(\mathbf{x}, \mathbf{y}) \\
0 & =g(\mathbf{x}, \mathbf{y})
\end{aligned}
$$

Where $g, f$ indicates the vectors of algebraic and differential equations. To perform small-signal analysis, the state matrix $\left(A_{s}\right)$ is determined from the Jacobian matrix $\left(A_{c}\right)$ obtained through the linearisation of DAE equations in (10) at the equilibrium point.

$$
\left[\begin{array}{c}
\Delta \dot{\mathbf{x}} \\
0
\end{array}\right]=\left[\begin{array}{ll}
f_{x} & f_{y} \\
g_{x} & g_{y}
\end{array}\right]\left[\begin{array}{c}
\Delta \mathbf{x} \\
\Delta \mathbf{y}
\end{array}\right]=A_{c}\left[\begin{array}{c}
\Delta \mathbf{x} \\
\Delta \mathbf{y}
\end{array}\right]
$$

Generation of $A_{s}$ is achieved through the process by avoiding the algebraic variables leading to the generic assumption that $g_{y}$ is not singular resulting in:

$$
A_{s}=f_{x}-f_{y} g_{y}^{-1} g_{x}
$$

The state matrix is then utilized to calculate the system eigenvalues. For a stable system, the eigenvalues are located on the left side of the $s$-domain.

- Fast Voltage Stability Index (FVSI): FVSI is adopted to ensure the safe and stable bus loading on the test systems under investigation [20,21], and is represented as Eq. (12).

$$
F V S I_{i j}=\frac{4 Z^{2} Q_{i}}{V_{i}^{2} X}
$$

Where $Q_{j}$ and $V_{i}$ indicates the reactive power and voltage at the $i$ th bus; $Z, X$ representing the system impedance and reactance respectively. A value of FVSI near to unity renders the system unstable, with FVSI exceeding beyond 1.00 indicates a trend towards sudden voltage drop at one of the buses connected to the network, potentially leading to system collapse. Incorporation of FVSI into the proposed controller ensures system stability under maximum loadability scenarios.

- Line Stability Index (LSI): LSI represented by $L_{m n}$ is developed based on the concept of power flow through a single line as described $[20,21]$ and can be written as Eq. (13),

$$
L_{m n}=\frac{4 Q_{r} X}{\left[\left|V_{s}\right| \sin (\theta-\delta)\right]^{2}}
$$

Here $X$ is the line reactance, $Q_{r}$ is the reactive power at the receiving end, $V_{s}$ is the sending end voltage, $\theta$ is the line impedance angle, and $\delta$ is the angle difference between the supply voltage and the receiving voltage. The value of $L_{m n}$ must be less than 1.00 to maintain a stable system. 
- Line stability factor (LSF): LSF is used to assess the network stability and is indicated as ( $\left.L_{Q P}\right)$ represented by Eq. (14). To preserve system stability the value of $L_{Q P}$ should be below 1.00 [21].

$$
L_{Q P}=4\left(\frac{X_{k}}{V_{k}^{2}}\right)\left(\frac{X_{k} P_{k}^{2}}{V_{k}^{2}}+Q_{k}\right)
$$

Here $X_{k}$ is the line reactance, $P_{k}$ and $Q_{k}$ are the real and reactive power, and $V_{k}$ the voltage at the $k^{\text {th }}$ bus.

\section{Test cases and simulation results}

\subsection{The IEEE standard 14-bus network}

The test system considered is the IEEE-14 bus standard test system as depicted in Fig. 4 and is modified by placing STATCOM at the bus no. 14, which is declared as generation bus. The system is suited for the proposed analysis as it contains transmission and distribution voltage levels, which allows observing the effect on transmission network by placing STATCOM in distribution. In the original system, it is found that bus no. 14 is one of the weakest buses and accordingly, for base case analysis STATCOM is connected to the same bus. The selection of weakest bus followed an intuition-based manual placement search based on assumptions such as there are no generators or compensator's available in the close vicinity of the candidate bus that can already provide reactive power support and also on the choice of the network voltage level to place the STATCOM. For more information on the selection of weak bus, the readers are referred to [17] and the reference therein.

The power flow analysis is done with the Newton-Raphson algorithm, which is coded in MATLAB platform. The load level without STATCOM at the base case is compared with the maximum loading incorporating GA controller as depicted in Fig. 5 and represented by the bars in blue and with STATCOM at maximum loading are represented by thick dark blue bars. From the results, it is clear that the load levels excluding load at the bus no. 11 in the test network are maximized and thus satisfying the optimization objective.

\subsubsection{Simulation of test case for IEEE standard 14-bus network}

The static simulation was performed with the modified 14-bus system as the base case and maximum loading scenarios with the real and reactive power measurements collated in Table 1 . As shown, more load demand can be accommodated with optimal allocation and setting of STATCOM, that is an additional active load demand of 1.59 p.u. can be supplied in the present case without the loss of the system stability, indicating a loading enhancement of $61.39 \%$. The voltage levels at the buses without and with the inclusion of STATCOM for maximum loading case are shown in Fig. 7. The results reveal the voltage improvement at the PV buses with optimal allocation of STATCOM to maximize the loading margin. As observed, for the maximum loadability scenario, voltage levels at all the buses stay in the regulatory limits of 0.9 p.u. - 1.1 p.u. The lowest level of voltage dip occurs at the bus. 3 owing to the highest load level on that particular bus.

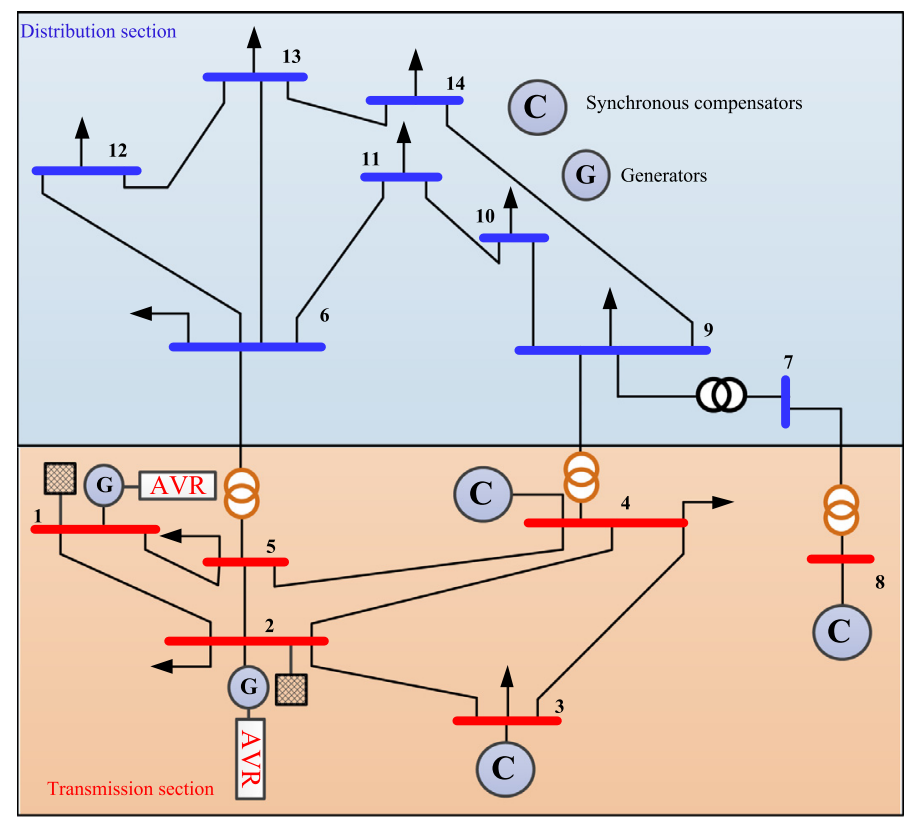

Fig. 4. IEEE 14 bus test system. 
Table 1

Real and reactive power characteristics at maximum loading.

\begin{tabular}{lllll}
\hline SystemLoadability & $P_{G}($ p.u.) & $Q_{G}($ p.u.) & $P_{L}($ p.u.) & $\mathrm{Q}_{L}($ p.u.) \\
\hline Base Scenario & 2.72 & 1.08 & 2.59 & 1 \\
Maximum Loading Scenario & 4.62 & 2.74 & 4.18 & 1.29 \\
Deviation (MAX - BASE Load) & 1.9 & 1.66 & 1.59 & 0.48 \\
\hline
\end{tabular}

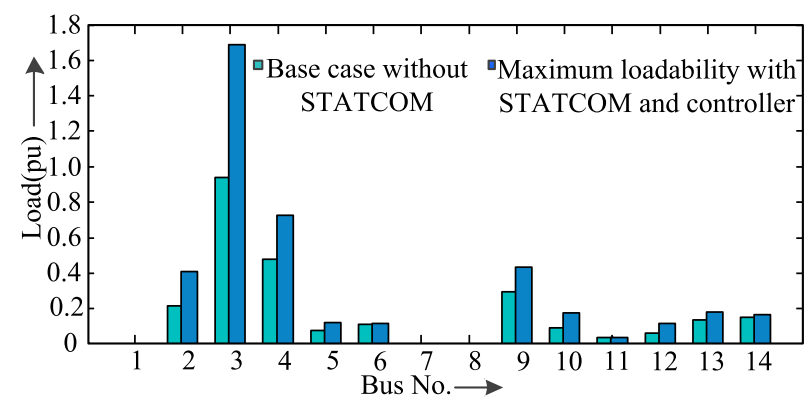

Fig. 5. Load levels with and without STATCOM.

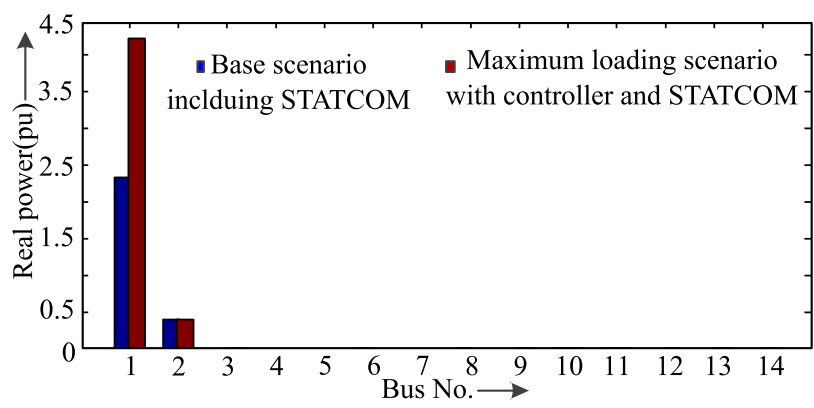

Fig. 6. Generation levels with and without STATCOM.

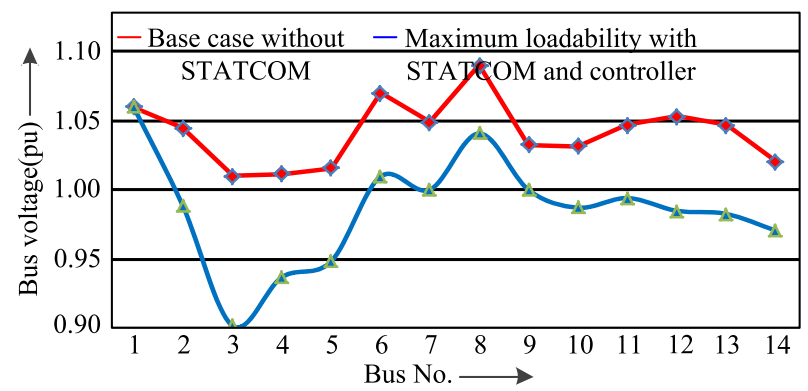

Fig. 7. Voltage levels with and without STATCOM.

The base case load, bus generation, voltage and real power levels with and without STATCOM, at the maximum loadability, are represented in Figs. 5-8. Compared to the base case, the additional load and the generation rise at the slack bus for accommodating the extra demand with STATCOM can be observed in Figs. 5 and 6 with corresponding voltage variation shown in Fig. 7. Fig. 8 shows the base case and maximum loadability line flow scenarios at different lines of the network with and without STATCOM, with optimal placement, increased power flow in all the line can be observed.

Small-signal stability incorporating optimal results characterized by the stability indices and eigenvalues are indicated in Figs. 9 and 10. It can be assured that with the inclusion of stability constraints to the optimization problem, for the best solution the system stability is preserved and represented by the location of eigenvalues as seen from Fig. 9 . Fig. 10 shows the stability constrained map for each line evidencing the system stability is maintained at maximum loading with the aid of STATCOM and controller. These characteristics validate the performance of the proposed controller in maintaining the grid stability under maximum loading conditions and ensures no bus or line overloading occurs with it. Table 2 gives the eigenvalues of IEEE standard 14 - bus network at different loading conditions. The table shows that as load increases, there is a tendency for the eigenvalues to shift to the right-hand side of $s$-plane, evidenced by damping ratio as well. 


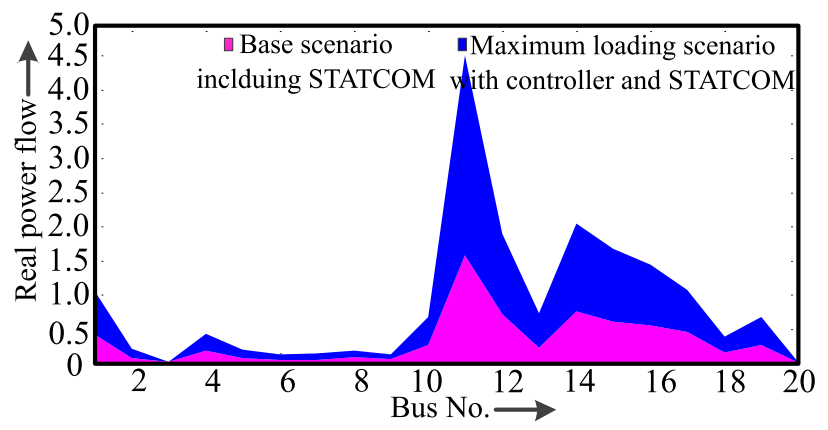

Fig. 8. Line real power flows with and without STATCOM.

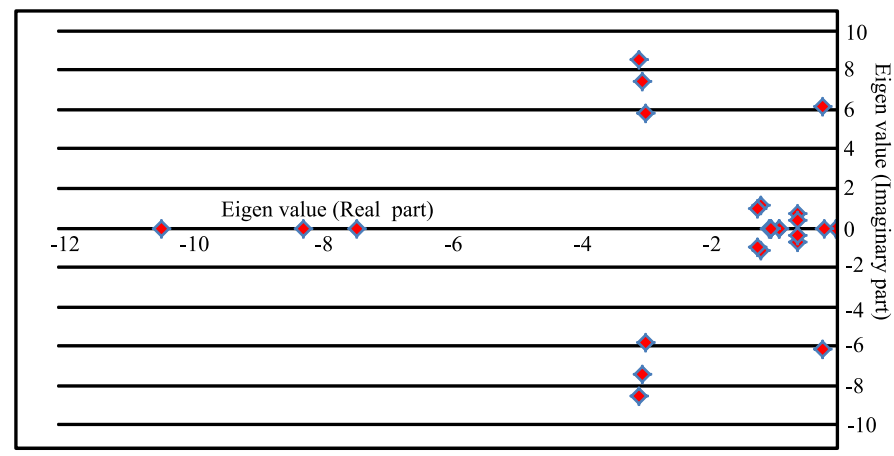

Fig. 9. Eigenvalues of the IEEE 14 bus test system.

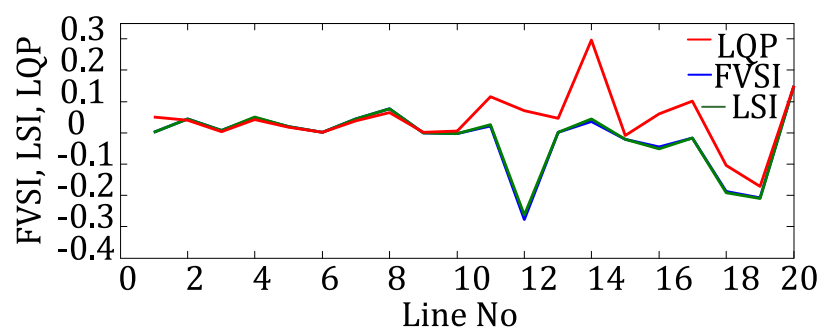

Fig. 10. Stability indices FVSI, LSI, LQP of IEEE 14 bus.

\subsection{Central Travancore-15 bus practical system}

The Central Travancore system (CTS) is a practical Indian utility power system located at Southern Kerala, India. The system as shown in Fig. 11 extends over four districts and is operated by the Kerala State Electricity Board (KSEB). There are 15 buses in the system including multiple hydropower generations located at bus no. 6 and 14, representing Idukki and Sabarigiri. Further, there are 18 lines, 1 Thermal power plant at Kayamkulam (bus no. 7) and 2 transformers. The hydro plants at Idukki and Sabarigiri are represented as slack buses [24,25]. A 40 MVAR shunt compensator is connected at Pallom substation (bus no.11) for reactive power support. At the Pallom substation, the $220 \mathrm{kV}$ high voltage is stepped down to 110 $k V$ to link the system with the distribution side. Static load modelling is used with a constant power factor (constant PQ) to represent the loads in the network. The system is one of the oldest system and hence it almost operating at its maximum capacity. This is the main scope of this study, which will be useful in for KSEB to find safe loading limit of the system and scope for retrofitting. The analysis of the system during the off-peak period is performed without considering thermal generation at the bus no. 11. The scheme is performed in multiple steps. The suitable location of STATCOM is identified in the first step followed by the computation of maximum loadability in all buses in the system. The best location of STATCOM to enhance loadability satisfying the constraints is found to be bus no. 1 .

\subsubsection{Static simulation of Central Travancore System:}

The maximum bus loading and generation scenario with and without STATCOM installation for CTS are illustrated in Figs. 12 and 13. Base case loading levels at buses without STATCOM in operation is compared with the maximum loading case with the inclusion of STATCOM. The plots reveal evidently that loading of different buses in the CTS system is almost 
Table 2

Eigenvalues of IEEE 14 bus network at various loading condition.

\begin{tabular}{|c|c|c|c|}
\hline Loading Condition & $\begin{array}{l}\text { Without STATCOM } \\
\text { \& Controller }\end{array}$ & $\begin{array}{l}\text { With } \\
\text { STATCOM }\end{array}$ & $\begin{array}{l}\text { With STATCOM } \\
\text { \& GA Controller }\end{array}$ \\
\hline Light Load & $\begin{array}{l}-5.13 \pm j 0 \\
(0.193) \\
-3.82 \pm j 8.29 \\
(0.162) \\
-1.90 \pm j 5.22 \\
(0.093) \\
-0.71 \pm j 0 \\
(0.034)\end{array}$ & $\begin{array}{l}-5.18 \pm j 0 \\
(0.187) \\
-4.16 \pm j 6.74 \\
(0.174) \\
-1.90 \pm j 5.41 \\
(0.097) \\
-0.71 \pm j 0.11 \\
(0.032)\end{array}$ & $\begin{array}{l}-7.40 \pm j 0 \\
(0.217) \\
-4 \pm j 9.2 \\
(0.170) \\
-1.2 \pm j 1.2 \\
(0.076) \\
-0.9 \pm j 0 \\
(0.057)\end{array}$ \\
\hline Normal Load & $\begin{array}{l}-4.55 \pm j 9.95 \\
(0.218) \\
-3.41 \pm j 9.12 \\
(0.211) \\
-1.01 \pm j 0 \\
(0.151) \\
-0.61 \pm j 0.74 \\
(0.053)\end{array}$ & $\begin{array}{l}-4.87 \pm j 9.44 \\
(0.196) \\
-3.57 \pm j 9.03 \\
(0.221) \\
-1.28 \pm j 0.20 \\
(0.166) \\
-0.82 \pm j 0 \\
(0.075)\end{array}$ & $\begin{array}{l}-7.40 \pm j 0 \\
(0.456) \\
-3.8 \pm j 9 \\
(0.210) \\
-1.28 \pm j 0.20 \\
(0.158) \\
-0.82 \pm j 0 \\
(0.081)\end{array}$ \\
\hline Heavy Load & $\begin{array}{l}-3 \pm j 6.14 \\
(0.144) \\
-1.08 \pm j 1.47 \\
(0.110) \\
-0.65 \pm j 0.35 \\
(0.083) \\
-0.18 \pm j 0 \\
(0.023)\end{array}$ & $\begin{array}{l}-3.16 \pm j 7.72 \\
(0.134) \\
-1.12 \pm j 1.28 \\
(0.113) \\
-0.86 \pm 0 \\
(0.081) \\
-0.19 \pm j 0 \\
(0.025)\end{array}$ & $\begin{array}{l}-3.49 \pm j 1.33 \\
(0.1768) \\
-1.23 \pm j 0 \\
(0.115) \\
-1 \pm j 0 \\
(0.10) \\
-0.29 \pm j 9.22 \\
(0.032)\end{array}$ \\
\hline
\end{tabular}

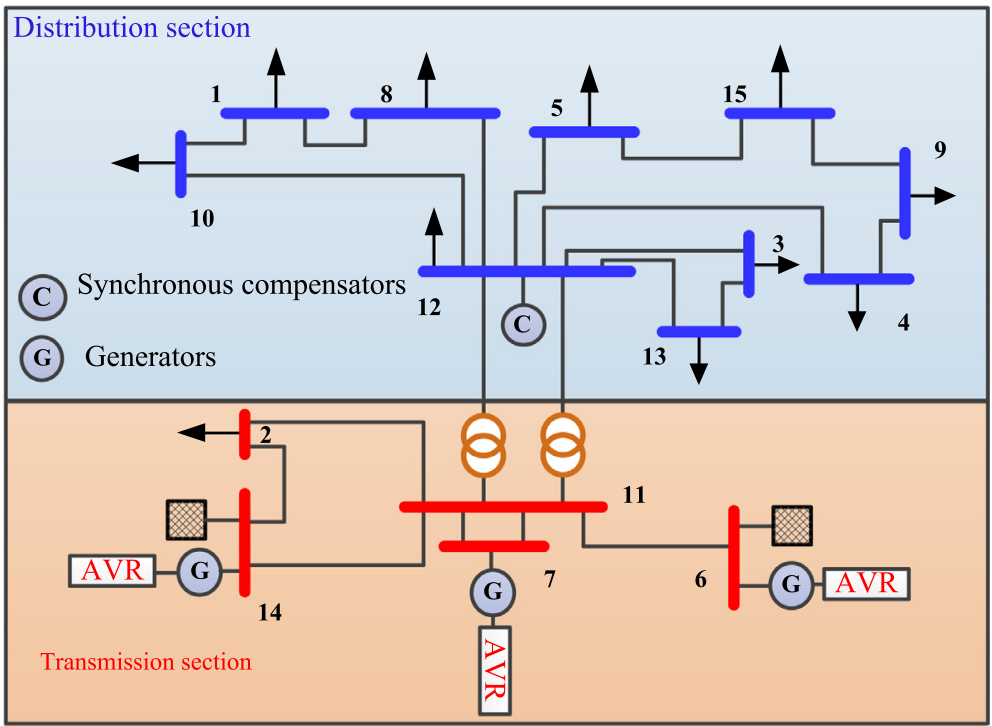

Fig. 11. Practical system of Central Travancore network.

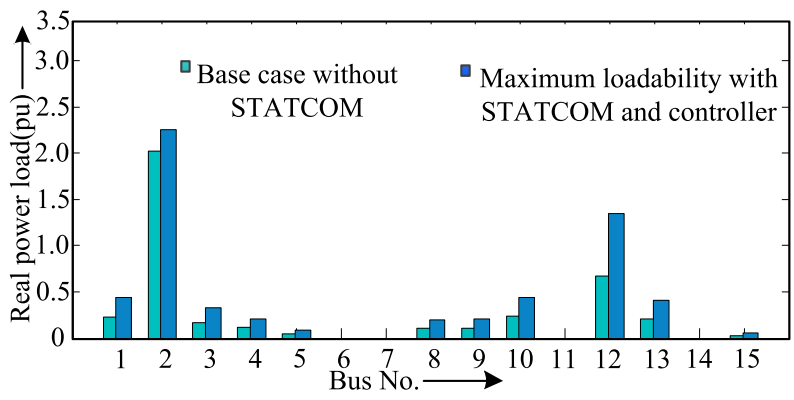

Fig. 12. Load levels with and without STATCOM. 


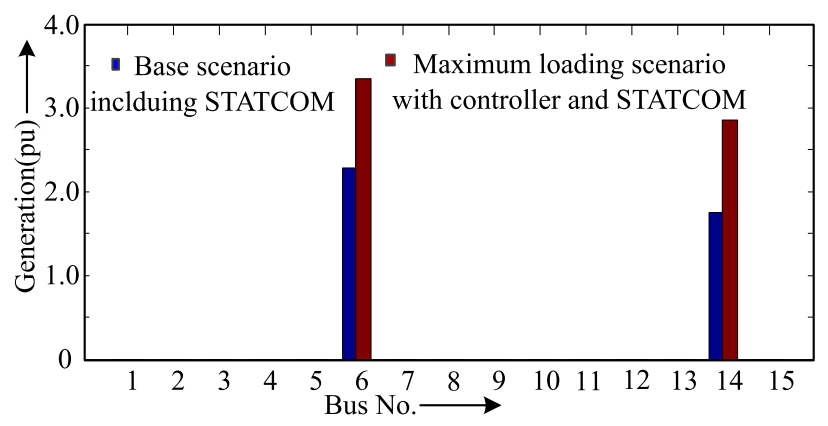

Fig. 13. Generation levels with and without STATCOM.

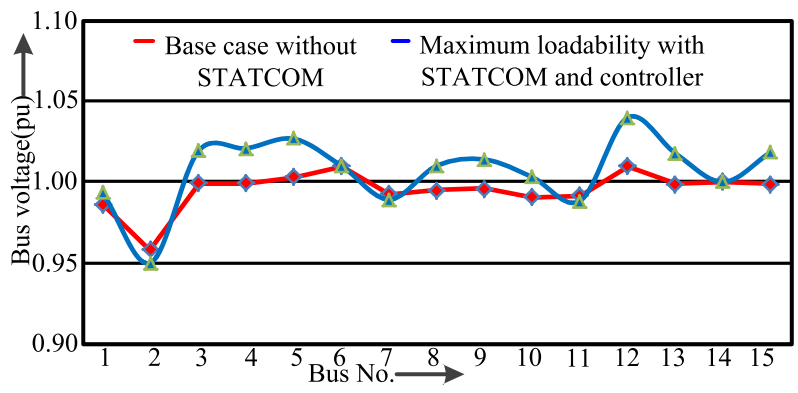

Fig. 14. Voltage levels with and without STATCOM.

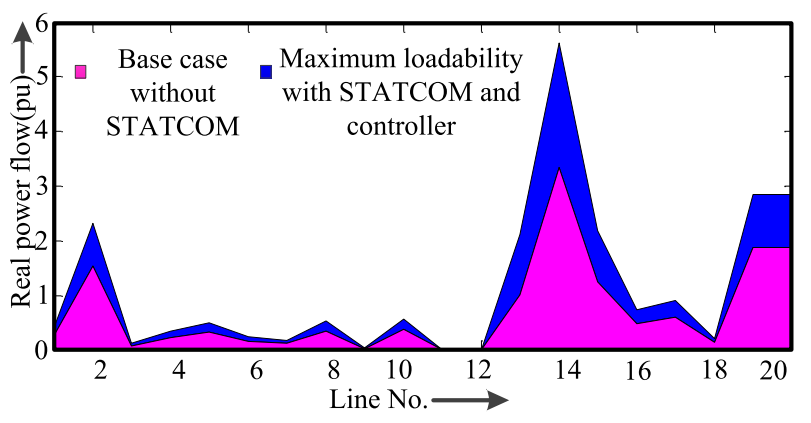

Fig. 15. Line real power flows with and without STATCOM.

at their maximum level, however, with STATCOM it can still be extended to allow more hosting. This amount of capacity enhancement is greatly appreciated by utilities as it gives more breathing area for the system operators. The total increase in capacity sums up-to 50\% of the current system load. Additionally bus no. 2 (Brahmapuram bus) is the highest load carrying bus in CTS. Fig. 14 depicts voltage levels at multiple buses for the maximum loading scenario and the base case without STATCOM. Optimal location slightly adjusts the voltage levels of the PV buses for maximizing the loading margin as depicted by the results. Moreover, it is demonstrated that the variations in voltage levels at the measured buses are well preserved within the regulatory limits of 0.95 p.u.-1.05 p.u. at maximum system loading with STATCOM. Fig. 15 presents the line flows in various lines of the system at peak loading through without and with STATCOM in operation. As observed, there is an increased capacity release after the incorporation of STATCOM at the bus no. 1, the optimal site.

Table 3 shows that additional load demand that can be attained in the CTS with optimal location and setting of STATCOM. That means a capacity enhancement of $2.04 \mathrm{p}$.u. without the violation of stability constraints corresponding to an increase of $51.27 \%$ real power level. Bus no. 2 shows a higher dip in voltage level due to the highest load. The generation in bus no. 6 (Idukki bus) is more than that in bus no. 14 (Sabarigiri bus).

The power system stability constraints and indices during optimal placement are indicated in Figs. 16 and 17. As evidenced in Fig. 16 with the association of stability constraints to the optimization problem, for the best solution the system stability is preserved determined by the location of eigenvalues. Moreover, the stability indices act within the satisfactory limits, as seen from Fig. 17. These characteristics validate the performance of the proposed controller in maintaining the grid stability under maximum loading conditions and ensures no bus and line overloading under various network operation. 
Table 3

Real and reactive power characteristics at maximum loading.

\begin{tabular}{lllll}
\hline SystemLoadability & $P_{G}($ p.u.) & $Q_{G}($ p.u.) & $P_{L}($ p.u.) & $\mathrm{Q}_{L}($ p.u.) \\
\hline Base Scenario & 4.04 & 1.74 & 3.94 & 1.43 \\
Maximum Loading Scenario & 6.19 & 3.78 & 5.96 & 2.36 \\
Deviation (MAX - BASE Load) & 2.15 & 2.04 & 2.02 & 0.93 \\
\hline
\end{tabular}

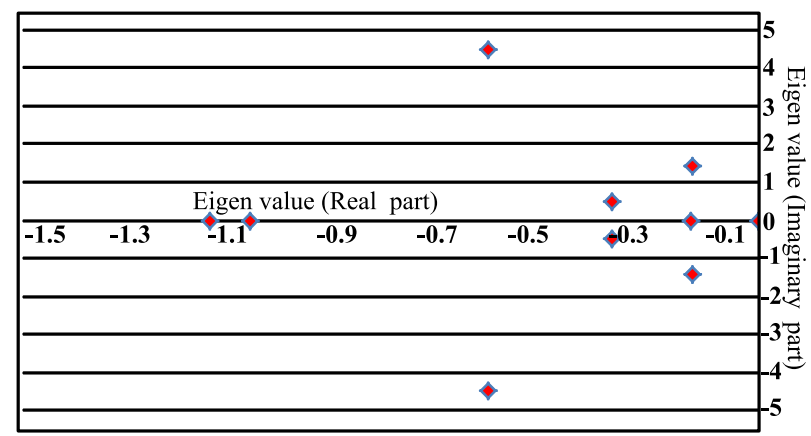

Fig. 16. Eigenvalues of the CTS test system.

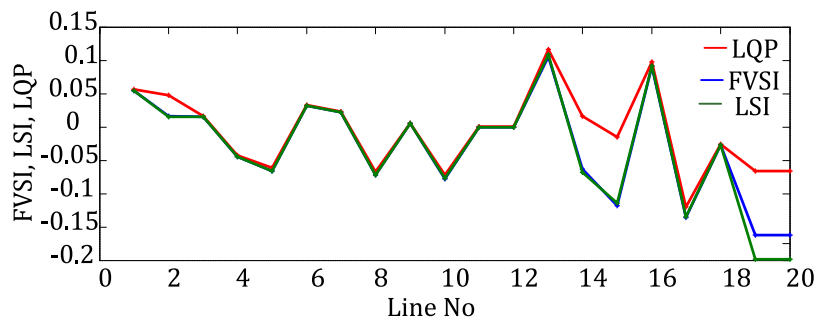

Fig. 17. Stability indices FVSI, LSI, LQP of CTS.

Further, the inclusion of the stability indices will increase the confidence of system operators to utilize the study presented here during a future retrofit.

The eigenvalues of the CTS at different loading conditions are shown in Table 4. The eigenvalues tend to move closer to the right half of $s$ - plane due to the increase in load. The introduction of STATCOM, as well as controller, regulates the eigenvalues to maintain the stable limit of the system.

\subsubsection{Dynamic simulation of Central Travancore System:}

Further to check the transient behaviour of STATCOM, dynamic simulations are performed. A fault case is studied with fault occurring at $t=1 \mathrm{~s}$ in bus no: 8 for a duration of $0.1 \mathrm{~s}$, considering a fault impedance $=0.24$ p.u in the practical test system. The fault impacts the security, energy quality as well as the reliability of the system and is fault impedance reliant. Fault impedance serves as the low resistant passage between ground or phase faults [22]. To retain the original state, different shunt compensators, for instance, the static capacitor, SC, SVC and STATCOM are placed at the bus no. 1 which is found to be the optimal location.

Fig. 18 indicates the voltage at nearby buses 1,5 and 8 with a static capacitor at bus no.1. The oscillations developed in the system are due to the presence of two synchronous generators. The action of the static capacitor helps to retain the bus voltage and requires a few seconds to settle. Fig. 19 shows the voltages for the case with SVC at bus no.1 in the CTS, the post fault voltage recovers within milliseconds, however, takes a few seconds to reaches steady-state.

The voltages with SC at the bus no. 1 are shown in Fig. 20. Similar to previous cases the SC maintains the pre-fault voltage after the $100 \mathrm{~ms}$ of fault duration, with an oscillation of lesser magnitude compared to the previous two cases. Fig. 21 shows the voltages at the three buses after the installation of a STATCOM at the bus no. 1. It provides compensation for bus voltages and helps to damp the oscillations generated in the system during a fault condition within a few cycles compared to other shunt devices. Figs. 18 to 21 prove that the dynamic behaviour of STATCOM is better than other shunt compensators as it can maintain the voltage at a fast rate during the fault condition. On the other hand, the peak of postfault voltage is large for the case with STATCOM, however, most of the equipment connected to the power system is designed to operate for larger voltage variation for a shorter period, thus minimizing the impact for this case. 
Table 4

Eigenvalues of CTS 15 bus system at different system loading.

\begin{tabular}{|c|c|c|c|}
\hline Loading condition & $\begin{array}{l}\text { Without STATCOM } \\
\text { \& Controller }\end{array}$ & $\begin{array}{l}\text { With } \\
\text { STATCOM }\end{array}$ & $\begin{array}{l}\text { With STATCOM } \\
\text { \& GA Controller }\end{array}$ \\
\hline Light Load & $\begin{array}{l}-13.21 \pm j 0 \\
(0.890) \\
-1.14 \pm j 0 \\
(0.140) \\
-0.77 \pm j 5.98 \\
(0.112) \\
-0.33 \pm j 0.33 \\
(0.069)\end{array}$ & $\begin{array}{l}-12.55 \pm j 0 \\
(0.822) \\
-1.15 \pm j 0 \\
(0.144) \\
-0.80 \pm j 5.87 \\
(0.121) \\
-0.33 \pm j 0.34 \\
(0.072)\end{array}$ & $\begin{array}{l}-12 \pm j 0 \\
(0.788) \\
-1.15 \pm j 0 \\
(0.147) \\
-0.81 \pm j 5.3 \\
(0.120) \\
-0.33 \pm j 0.40 \\
(0.068)\end{array}$ \\
\hline Normal Load & $\begin{array}{l}-13.21 \pm j 0 \\
(0.651) \\
-1.05 \pm j 0 \\
(0.172) \\
-0.77 \pm j 5.9 \\
(0.13) \\
-0.33 \pm j 0.32 \\
(0.053)\end{array}$ & $\begin{array}{l}-13.55 \pm j 0 \\
(0.611) \\
-1.15 \pm j 0 \\
(0.177) \\
-0.63 \pm j 6.24 \\
(0.127) \\
-0.33 \pm j 0.41 \\
(0.047)\end{array}$ & $\begin{array}{l}-11.3 \pm j 0 \\
(0.662) \\
-1.10 \pm j 0 \\
(0.117) \\
-0.8 \pm j 5.3 \\
(0.137) \\
-0.33 \pm j 0.41 \\
(0.055)\end{array}$ \\
\hline Heavy Load & $\begin{array}{l}-1.13 \pm j 0 \\
(0.183) \\
-0.65 \pm j 6.1 \\
(0.131) \\
-0.33 \pm j 0.44 \\
(0.053) \\
-0.28 \pm j 0.93 \\
(0.016)\end{array}$ & $\begin{array}{l}-1.12 \pm j 0 \\
(0.181) \\
-0.65 \pm j 6.1 \\
(0.127) \\
-0.331 \pm j 0.45 \\
(0.049) \\
-0.28 \pm j 0.94 \\
(0.018)\end{array}$ & $\begin{array}{l}-1.36 \pm j 0 \\
(0.220) \\
-0.65 \pm j 6.1 \\
(0.139) \\
-0.36 \pm j 8.18 \\
(0.051) \\
-0.29 \pm j 9.22 \\
(0.017)\end{array}$ \\
\hline
\end{tabular}

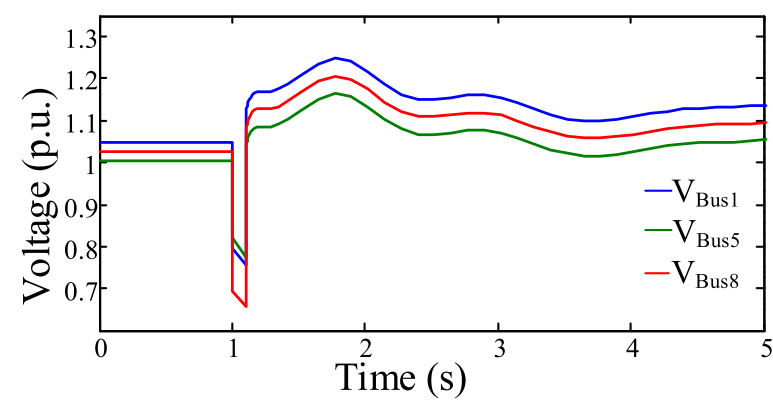

Fig. 18. Voltages profile after the installation of Capacitor at bus no. 1.

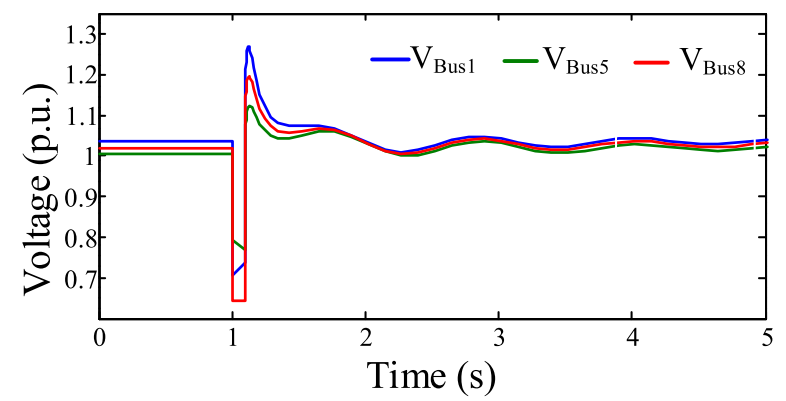

Fig. 19. Voltages profile after the installation of SVC at bus no. 1.

\section{Algorithm comparison}

Table 5 and 6 draws a comparison of the base-case without STATCOM and GA controller and controller equipped with different algorithms. The case study has been performed for both IEEE 14 bus and CTS system. The network parameters such as total generation, power losses, voltage limits, loadability and location were used for comparative study. In addition, the computational time for different algorithms to solve the optimal placement problem is also considered. As shown, in general GA outperforms other methods and is therefore selected for this work. Moreover, the results evidences effective 


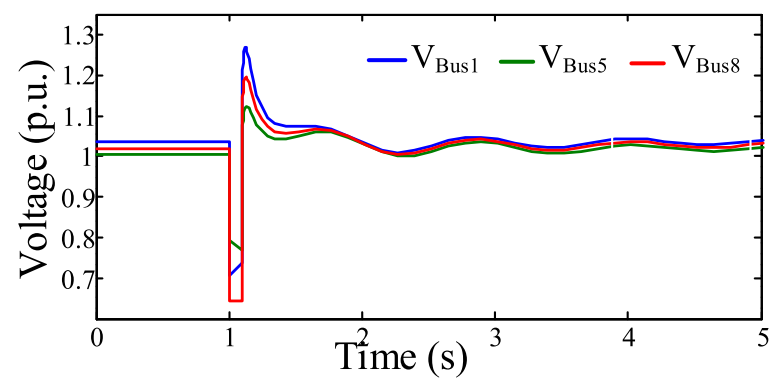

Fig. 20. Voltages profile with SC at bus no. 1.

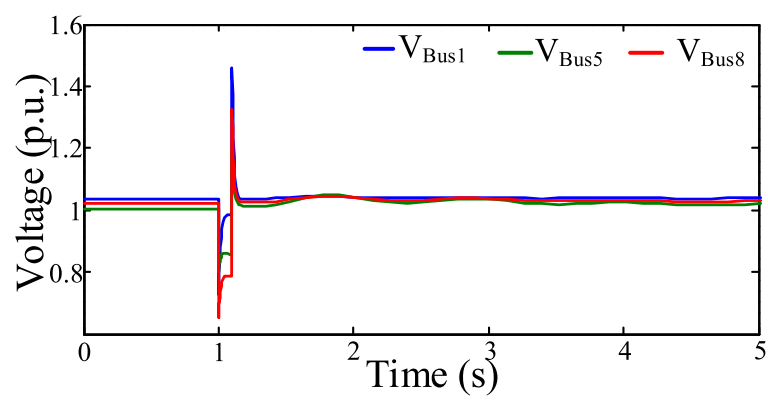

Fig. 21. Voltages profile with installation of STATCOM at bus no. 1.

Table 5

Different algorithms comparison for IEEE- 14 bus test system.

\begin{tabular}{|c|c|c|c|c|c|c|c|c|}
\hline \multirow[t]{3}{*}{ Parameter } & \multirow[t]{3}{*}{ Unit } & \multirow{3}{*}{$\begin{array}{l}\text { Base } \\
\text { case }\end{array}$} & \multicolumn{6}{|c|}{ Compensated } \\
\hline & & & \multicolumn{2}{|c|}{ Total Iteration } & \multirow{2}{*}{$\begin{array}{l}50 \\
\mathrm{DE}\end{array}$} & \multicolumn{2}{|c|}{ Population Size } & \multirow{2}{*}{$\begin{array}{l}30 \\
\text { PSO }\end{array}$} \\
\hline & & & $\mathrm{ABC}$ & ACOR & & GA & HS & \\
\hline Total Generation & $\mathrm{kW}$ & 2.725 & 5.48 & 5.685 & 5.472 & 5.599 & 5.701 & 5.66 \\
\hline Total Active Losses & p.u & 0.135 & 0.469 & 0.507 & 0.471 & 0.489 & 0.535 & 0.499 \\
\hline Minimum Bus Voltage & p.u & 1.01 & 0.93 & 0.910 & 0.937 & 0.900 & 0.939 & 0.9082 \\
\hline Maximum Bus Voltage & p.u & 1.09 & 1.09 & 1.077 & 1.065 & 1.065 & 1.090 & 1.06 \\
\hline Maximum Loadability & p.u & 2.59 & 5.014 & 5.1779 & 5.000 & 5.110 & 5.166 & 5.1656 \\
\hline FACTS Location & Bus No. & & 14 & 14 & 14 & 14 & 14 & 14 \\
\hline No. of Function Evaluations & Nos. & & 2530 & 2530 & 1530 & 1580 & 2030 & 1530 \\
\hline Algorithm Run Time & $\mathrm{Sec}$ & & 2917.11 & 2923.56 & 1734.97 & 1637.85 & 2150.17 & 1595.05 \\
\hline
\end{tabular}

Table 6

Different algorithms comparison for CTS test system.

\begin{tabular}{|c|c|c|c|c|c|c|c|c|}
\hline \multirow[t]{3}{*}{ Parameter } & \multirow[t]{3}{*}{ Unit } & \multirow{3}{*}{$\begin{array}{l}\text { Base } \\
\text { case }\end{array}$} & \multicolumn{6}{|c|}{ Compensated } \\
\hline & & & \multicolumn{2}{|c|}{ Total Iteration } & \multirow{2}{*}{$\begin{array}{l}50 \\
\text { DE }\end{array}$} & \multicolumn{2}{|c|}{ Population Size } & \multirow{2}{*}{$\begin{array}{l}30 \\
\text { PSO }\end{array}$} \\
\hline & & & $\mathrm{ABC}$ & ACOR & & GA & HS & \\
\hline Total Generation & $\mathrm{kW}$ & 4.001 & 4.885 & 4.88 & 4.88 & 4.88 & 4.893 & 4.890 \\
\hline Total Active Losses & p.u & 0.063 & 0.135 & 0.13 & 0.129 & 0.128 & 0.132 & 0.132 \\
\hline Minimum Bus Voltage & p.u & 0.955 & 0.909 & 0.912 & 0.91 & 0.90 & 0.912 & 0.916 \\
\hline Maximum Bus Voltage & p.u & 1.01 & 1.094 & 1.070 & 1.094 & 1.05 & 1.0974 & 1.091 \\
\hline Maximum Loadability & p.u & 3.938 & 4.750 & 4.760 & 4.760 & 4.75 & 4.760 & 4.758 \\
\hline FACTS Location & Bus No. & & 1 & 1 & 1 & 1 & 1 & 1 \\
\hline No. of Function Evaluations & Nos. & & 2530 & 2530 & 1530 & 1580 & 2030 & 1530 \\
\hline Algorithm Run Time & Sec & & 1077.62 & 1078.7 & 647.36 & 743.1 & 877.41 & 663.29 \\
\hline
\end{tabular}

Table 7

Parameters of STATCOM current-injection model.

\begin{tabular}{llll}
\hline Variable & Description & Value & Unit \\
\hline$K_{r}$ & Gain constant of regulator & 50 & p.u./p.u. \\
$i^{\max }$ & Peak current & 0.2 & p.u. \\
$i^{\min }$ & Minimum current & -0.2 & p.u. \\
$T_{r}$ & Time constant of regulator & 0.1 & $\mathrm{~s}$ \\
\hline
\end{tabular}


performance of proposed algorithm in finding better location of STATCOM while achieving maximum loadability. Besides, the controller is capable for reducing systems power loss from $23.28 \%$ to $11.32 \%$.

\section{Conclusion}

A direct relation between the safe loading margin and stability limits in power systems has been demonstrated in this paper with the help of static and dynamic simulations. A placement methodology based on GA has been implemented to maximize the transmission system loadability through identifying the best location of STATCOM controllers. GA is utilized owing to its simplicity and effectiveness to solve non-linear optimization problems. The proposed algorithm presented in this work helped to detect the optimal solutions efficiently with an improvement in the overall system capabilities. Moreover, the paper demonstrated the capability of adequately supporting the network voltage by properly placing shunt FACTS devices. The effectiveness has been proved through a practical system application. Results of the present investigation revealed that:

1. With the introduction of STATCOM an improvement in the system loadability with stable voltage profile has been achieved for both IEEE 14 bus and CTS.

2. An additional $61 \%$ capacity is released with the proposed scheme in the IEEE 14 bus network, compared to $51 \%$ in the CTS to host the increased renewable resources.

3. Small signal stability, FVSI, LSI and LQP based indexes incorporated in the optimization guarantees stable network operation under varying loading margins and contributes to improved operator confidence for STATCOM integration.

4. The requirement for selecting the weakest and strongest bus for the placement of STATCOM for stable grid operation is highlighted and studied with theoretical (eigenanalysis) and simulation approaches.

The study is considered as a preliminary technical analysis for FACTS device placement in Kerala grid and will be followed by a techno-economic feasibility study and detailed mathematical modelling of the FACTS devices to be considered as a future work alongside the application of multi-objective optimization approach for placement of FACTS devices.

\section{Declaration of Competing Interest}

The authors declare that they have no known competing financial interests or personal relationships that could have appeared to influence the work reported in this paper.

\section{Appendix A}

Table 7 provides the current-injection STATCOM parameters.

\section{Supplementary material}

Supplementary material associated with this article can be found, in the online version, at doi:10.1016/j.compeleceng. 2019.106521.

\section{CRediT authorship contribution statement}

Sasidharan Sreedharan: Methodology, Software, Supervision. Tibin Joseph: Data curation, Writing - original draft, Writing - review \& editing, Supervision. Sebin Joseph: Formal analysis, Data curation, Investigation. Chittesh Veni Chandran: Conceptualization, Data curation, Writing - original draft. Vishnu J: Data curation, Writing - original draft. Vipin Das P: Writing - review \& editing.

\section{References}

[1] Guguloth R, Kumar TKS. Congestion management in restructured power systems for smart cities in india. Comput Electr Eng 2018;65:79-89.

[2] Mishra P, Ghose T. A direct method for assessment of overall voltage condition of power system. Int J Electr Power Energy Systems 2016;81:232-8.

[3] Shwehdi MH, Mohamed SR, Devaraj D. Optimal capacitor placement on west east inter-tie in saudi arabia using genetic algorithm. Comput Electr Eng 2018;68:156-69.

[4] Singh B, Mukherjee V, Tiwari P. A survey on impact assessment of DG and FACTS controllers in power systems. Renew Sustain Energy Rev 2015;42:846-82.

[5] Dixit M, Kundu P, Jariwala HR. Optimal integration of shunt capacitor banks in distribution networks for assessment of techno-economic asset. Comput Electr Eng 2018;71:331-45.

[6] Joseph S, Skariah EN, Joseph T, Sreedharan S, Chandran CV, Das PV, Vishnu J. PSO based controller algorithm for optimal allocation \& setting of fue cell in a wind PV integrated power system for maximizing loadability. In: Proceedings of the international conference on advances in green energy (ICAGE). Thiruvananthapuram; 2014. p. 1-6.

[7] Paul J, Joseph T, Sreedharan S. PSO based generator rescheduling for relieving transmission overload. In: Proceedings of the international mutli-conference on automation, computing, communication, control and compressed sensing (iMac4s). Kottayam; 2013. p. 409-14.

[8] Abd-Elazim SM, Ali ES. Imperialist competitive algorithm for optimal STATCOM design in a multimachine power system. Int J Electr Power Energy Syst 2016;76:136-46. 
[9] Abd-Elazim SM, Ali ES. Improved harmony algorithm and power loss index for optimal locations and sizing of capacitors in radial distribution systems. Int J Electr Power Energy Syst 2016;80:252-63.

[10] Abd-Elazim SM, Ali ES. Optimal location of STATCOM in multimachine power system for increasing loadability by cuckoo search algorithm. Int J Electr Power Energy Syst 2016:80:240-51.

[11] Amir M, Niasar AH, Gharehpetian GB. Designing SSSC, TCSC, and STATCOM controllers using AVURPSO, GSA, and GA for transient stability improvement of a multi-machine power system with PV and wind farms. Int J Electr Power Energy Syst 2019;106:455-66

[12] Chang YC. Transmission system loading margin enhancement with ordinal optimization based STATCOM installation strategy. Int J Electr Power Energy Syst 2014;55:503-10.

[13] Mohammed A, Albughdadi M, Isa NAM. Variance-based differential evolution algorithm with an optional crossover for data clustering. Appl Soft Comput 2019;80:1-17.

[14] Shefaei A, Vahid-Pakdel MJ, Mohammadi-ivatloo B. Application of a hybrid evolutionary algorithm on reactive power compensation problem of distribution network. Comput Electr Eng 2018;72:125-36.

[15] Shekhar JI, Kishore SY, Manju G. Dynamic compensation in indian power system - siting \& sizing. Power grid corporation of india limited. CIGRE; 2014.

[16] Shahnia F, Rajakaruna S, Ghosh A. Static compensators (STATCOMs) in power systems. Springer; 2015. ISBN: 978-981-287-280-7 (Print) 978-981-287-281-4 (Online).

[17] Sode-Yome A, Mithulananthan N, Lee KY. Static voltage stability margin enhancement using STATCOM, TCSC and SSSC. In: Proceedings of the IEEE/ PES transmission and distribution conference \& exhibition: Asia and Pacific Dalian. China; 2005. p. 0-4.

[18] Kundur P. Power system stability and control. McGraw-Hill; 1994. ISBN: 0-07-035958.

[19] Milano F. Power system modeling and scripting. Springer; 2010. ISBN: 978-3-642-13668-9.

[20] Ratra S, Tiwari R, Niazi KR. Voltage stability assessment in power systems using line voltage stability index. Comput Electr Eng 2018;70:199-211.

[21] Mohssen SS, Haghifam M, Salehi J. Simultaneous placement of distributed generation and capacitors in distribution networks considering voltage stability index. Int J Electr Power Energy Syst 2013;46:366-75.

[22] Filomena AD, Resener M, Salim RH, Bretas AS. Distribution systems fault analysis considering fault resistance estimation. Int J Electr Power Energy Syst 2011;33:326-1335.

[23] Kaushik K, Yadav N. Voltage stability enhancement using VSC-OPF including wind farms based on genetic algorithm. Int J Electr Power Energy Syst 2015;73:560-7.

[24] Pillai AG, Thomas PC, Sreerenjini K, Baby S, Joseph T, Sreedharan S. Transient stability analysis of wind integrated power systems with storage using central area controller. In: Proceedings of the annual international conference on emerging research areas and microelectronics, communications and renewable energy. Kanjirapally; 2013. p. 1-5.

[25] Baby A, Thomas J, Joseph T. Analysis of voltage collapse in the kerala power grids. In: Proceedings of the international conference on computer communication and informatics. Coimbatore; 2013. p. 1-5.

Sasidharan Sreedharan received his Masters in Power System from Govt Engineering College, Kerala, India in 1998 and Ph.D. from Asian Institute of Technology, Bangkok, in 2010 respectively. He was post doctoral researcher in RED Laboratory, University of Hawaii, United States from 2014 to 2015. His Research interests are in grid integration of Renewables, AI and ML applications to power systems and grid stability.

Tibin Joseph received Masters degree in Power Electronic and Power Systems from Mahatma Gandhi University, Kerala, India, in 2011 and Ph.D. degree from Cardiff University, U.K. in 2018. He was a Marie Curie Early Stage Researcher between 2013-2016 at Cardiff University. Since 2016 he has been working as a Postdoctoral Researcher at Cardiff University in Energy Networks and Power Electronics.

Sebin Joseph received the B.Tech. degree in Electrical \& Electronics Engineering and M.Tech. degree in Power Systems from Mahatma Gandhi University, Kerala, India in 2011 and 2014, respectively. From December 2014 he is working as an Electrical Engineer at Al Ahleia Switchgear, Kuwait.

Chittesh Veni Chandran received his Masters degree in Power Systems from Mahatma Gandhi University, India in 2014. He joined the TU Dublin, Ireland as a Ph.D. Researcher in December 2015 and is currently working as Assistant Lecturer. His research areas include renewable energy, demand side management, electricity market analysis, harmonic analysis, and optimization methods application in power systems.

Vishnu J received the B.Tech. degree in Electrical \& Electronics Engineering and Masters degree in Power Systems from Mahatma Gandhi University, Kerala, India in 2008 and 2014, respectively. From December 2017 he is working as an Engineer with Kerala State Electricity Board, Kerala, India.

Vipin Das received the Masters degree in power systems from Mahatma Gandhi University, India, in 2014. He is currently working towards his Ph.D. degree at Motilal Nehru National Institute of Technology Allahabad, India. His research interests include power electronics converters for renewable energy systems, power system optimization and power system energy management. 